\title{
Safety evaluation of seabuckthorn (Hippophae rhamnoides) leaves in Japanese quail
}

\author{
Vikram Patial ${ }^{1}$, R. K. Asrani ${ }^{2}$ and Rajendra Damu Patil ${ }^{2}$ \\ 1. Biotechnology Division, CSIR-Institute of Himalayan Bioresource and Technology, Palampur-176 061 \\ (Himachal Pradesh) India ; 2. Department of Veterinary Pathology, Dr G. C. Negi College of Veterinary and Animal \\ Sciences, CSK Himachal Pradesh Agricultural University, Palampur (Himachal Pradesh) India. \\ Corresponding author: Vikram Patial, Tel: + 91- 9418663900, Email: drvikrampatial@yahoo.in \\ Received: 29-01-2013, Revised: 24-02-2013, Accepted: 26-02-2013, Published online: 18-06-2013
}

\section{How to cite this article:}

Patial V, Asrani RK and Patil RD (2013) Safety evaluation of seabuckthorn (Hippophae rhamnoides) leaves in Japanese quail, Vet World 6(9): 596-600, doi: 10.5455/vetworld.2013.596-600

\begin{abstract}
Aim: The present study was designed to evaluate the safety of seabuckthorn (SBT) (Hippophae rhamnoides L. Elaeagnaceae) leaves added in the diet of Japanese quail.

Materials and Methods: A total of ninety quail chicks were randomly divided into 2 groups and fed a standard quail chick mash added with or without $2 \%$ SBT leaf powder (Group SX), and a standard quail chick mash (Group CX, control) for 21 days. Six animals from each group were randomly sacrificed at 7, 14 and 21 day post feeding. Blood and tissue samples were collected for biochemical and histopathological studies.

Results: The inclusion of SBT in quail diet did not affect the weekly body weights, clinical signs or mortality among the birds. The serum biochemical parameters like alanine transaminase, total protein, albumin, cholesterol and uric acid values in SBT treated group were found at par with those in the control group. Gross and histopathological studies of various internal organs such as liver, kidneys, heart, spleen, proventriculus, small intestine, bursa and thymus did not reveal any significant lesions in the tissue sections. However, proliferation of lymphoid tissue was a prominent finding noted in different lymphoid organs.
\end{abstract}

Conclusion: In conclusion, the addition of seabuckthorn leaf powder at $2 \%$ level in the diet of Japanese quail was found to be safe and it can be used as a feed additive.

Keywords: biochemical changes, Japanese quail, pathology, seabuckthorn

\section{Introduction}

Seabuckthorn (Hippophae rhamnoides) (SBT) is a naturally growing shrub that is native to Eastern Europe and Asia and is found in the high altitudes of Indian Himalayan region. It is not only adaptable to high altitude region, but its leaves and fruit also contain abundant of nutrients. SBT is widely used in traditional medicine for the treatment of cardiovascular diseases, flu, mucosal injuries, skin disorders, hepatotoxicity and hypoglycemia $[1,2,3]$ All parts of this wonder plant are considered to be a good source of a large number of bioactive compounds, including carotenoids, tocopherols, sterols, flavonoids, lipids, vitamins, tannins, minerals, etc. which contributes to its wide usage as a natural antioxidant $[3,4,5]$. SBT leaves are rich in flavonoids, tannins and triterpenes [6] and possess antioxidant and immunomodulatory [7], anti-stress and antiinflammatory activity [8]. SBT byproducts were also found to ameliorate the toxic effect of different toxins in poultry feed $[9,10]$. Studies showed that the leaves and fruit residues of SBT could be used to feed poultry

This article is an open access article licensed under the terms of the Creative Commons Attribution License (http://creativecommons. org/licenses/by/2.0) which permits unrestricted use, distribution and reproduction in any medium, provided the work is properly cited. and livestock without the accumulation of toxins, and that the feed also had a stimulating effect on growth and performance of poultry and livestock [11, 12]. Guan et al [13]. found that SBT fresh leaves are rich in total carotenoids $(26.3 \mathrm{mg} / 100 \mathrm{~g})$ and total chlorophyll (98.8 $\mathrm{mg} / 100 \mathrm{~g}$ ), an indicator of quality for green vegetables; whereas dried leaves still contained large quantities of bioactive compounds comparable to commonly consumed vegetables. Hippophae leaves also contain significant amounts of proteins $(20.7 \%)$, amino acids (0.73\% lysine, $0.13 \%$ methionine and cystine) [12], minerals $(\mathrm{Ca}, \mathrm{Mg}$ and $\mathrm{K})$, folic acid, catechins, esterified sterols, triterpenols and isoprenols [13,14]. According to Kumar et al. [15], the tannins hippophaenins A and B were isolated from SBT leaves.

Poultry farming is an important industry in most of the provinces and regions of India. The poultry industry has made rapid strides in last two decades in India which has been possible due to good breeds of birds, balanced diet, good health care and management practices. Addition of seabuckthorn on a routine basis in poultry diet would depend upon its beneficial effects on growth response and immunomodulation. In recent years less attention has been paid to the use of SBT as a poultry and livestock feed, therefore determination of 


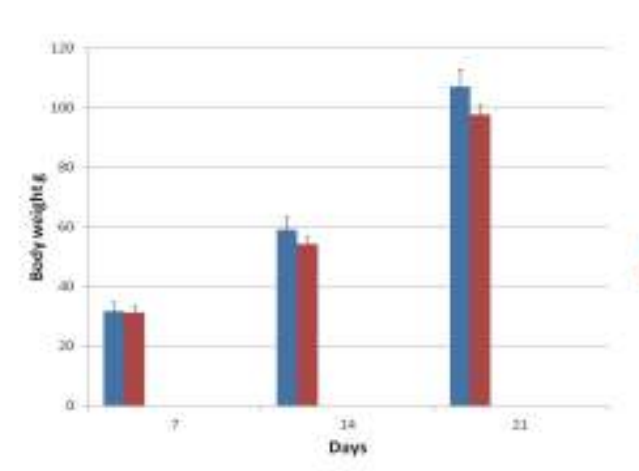

Figure-1. Effect of feeding SBT leaves on body weights (Mean \pm SEM) of Japanese quail at different intervals $(\mathrm{N}=9)$.

Table-1. Effect of seabuckthorn on different biochemical parameters in Japanese quail at different intervals.

\begin{tabular}{lllll}
\hline Parameters & Groups & \multicolumn{3}{c}{ Days post feeding } \\
\cline { 2 - 5 } & & 7 DPF & 14 DPF & 21 DPF \\
\hline ALT & CX & $10.50 \pm 0.95^{\mathrm{a}}$ & $12.50 \pm 0.95^{\mathrm{a}}$ & $8.83 \pm 0.94^{\mathrm{a}}$ \\
U/l & SX & $12.66 \pm 0.61^{\mathrm{a}}$ & $12.83 \pm 0.60^{\mathrm{a}}$ & $7.00 \pm 0.57^{\mathrm{a}}$ \\
Cholesterol & $\mathrm{CX}$ & $166.33 \pm 4.95^{\mathrm{a}}$ & $212.16 \pm 15.82^{\mathrm{a}}$ & $128.83 \pm 9.74^{\mathrm{a}}$ \\
$\mathrm{mg} / \mathrm{dl}$ & $\mathrm{SX}$ & $193.00 \pm 13.21^{\mathrm{a}}$ & $215.66 \pm 17.4^{\mathrm{a}}$ & $149.50 \pm 8.86^{\mathrm{a}}$ \\
Total Protein & $\mathrm{CX}$ & $2.91 \pm 0.18^{\mathrm{a}}$ & $3.35 \pm 0.13^{\mathrm{a}}$ & $3.36 \pm 0.18^{\mathrm{a}}$ \\
g/dl & $\mathrm{SX}$ & $2.90 \pm 0.05^{\mathrm{a}}$ & $3.40 \pm 0.16^{\mathrm{a}}$ & $3.46 \pm 0.08^{\mathrm{a}}$ \\
Albumin & $\mathrm{CX}$ & $1.43 \pm 0.06^{\mathrm{a}}$ & $1.56 \pm 0.07^{\mathrm{a}}$ & $1.46 \pm 0.04^{\mathrm{a}}$ \\
g/dl & $\mathrm{SX}$ & $1.65 \pm 0.06^{\mathrm{b}}$ & $1.51 \pm 0.04^{\mathrm{a}}$ & $1.43 \pm 0.06^{\mathrm{a}}$ \\
Uric acid & $\mathrm{CX}$ & $7.46 \pm 0.46^{\mathrm{a}}$ & $4.53 \pm 0.72^{\mathrm{a}}$ & $5.12 \pm 0.62^{\mathrm{a}}$ \\
mg/dl & $\mathrm{SX}$ & $7.28 \pm 1.26^{\mathrm{a}}$ & $5.66 \pm 1.27^{\mathrm{a}}$ & $3.93 \pm 0.48^{\mathrm{a}}$ \\
\hline
\end{tabular}

$a-b$ Values within columns for different parameters (between groups $C X$ and $S X$ ) with different superscripts are significantly different by student's t- test $(P<0.05)$. Data are means $\pm \mathrm{SE}$ of three replicate pens of 2 quail each. $\mathrm{CX}=$ control group; $\mathrm{SX}=$ Seabuckthorn group

the safety and nutritive value of SBT will provide valuable information that can be used to promote its use as livestock and poultry feed additive [12].

Present study was planned for the safety evaluation of SBT leaf powder in the feed of Japanese quail on the basis of clinic-pathological study so that it can be promoted as a feed additive in the poultry feed.

\section{Materials and Methods}

Ethical approval: The animal care and experimental protocol was approved by institutional animal ethical committee as per CPCSEA guidelines.

Experimental birds and their management: Ninety, day-old Japanese quail chicks belonging to the same breeding flock were purchased from Central Poultry Development Organization, Chandigarh, India. Prior to arrival of day-old chicks, the experimental room, cages, trays and cage stands were thoroughly cleaned with water, $2.5 \%$ phenol, dried under sunlight, and flamed with dry heat using a blowlamp. The room was fumigated with formaldehyde gas, just one day prior to arrival of quail chicks. The waterers and feeders were cleaned daily with $5 \% \mathrm{KMnO}_{4}$ solution throughout the experiment.

Plant material: Seabuckthorn ( $H$. rhamnoides L.) leaves were collected from the orchard of Krishi Vigyan Kendra (KVK), CSK HP Krishi Vishwavidyalaya, Kukumseri, District Lahaul, Himachal Pradesh, India at an altitude of 8866 feet from mean seal level. Fresh leaves were dried under shade in a clean, dust free environment and ground to fine powder. The plant material was also submitted for biochemical estimation to Department of Biotechnology, Amrita University, Kollam, Kerala, India. The sample was found to contain with flavonoids such as quercetin $(0.020 \%)$, kaempferol $(0.015 \%)$ and isorhamnetin $(0.15 \%)$ using High Performance Liquid Chromatography (HPLC).

Feeding schedule: The quail chicks were fed dietary treatments (Quail mash procured from Department of Animal Nutrition, College of Veterinary Scienc, CSK HP Krishi Vishwavidyalaya, Palampur amended with the appropriate additives) from day 1 until the end of the experiment. Feed was autoclaved before feeding or mixing SBT powder. Pre-boiled drinking water was provided to the chicks during the experiment. Feed and water were available for ad libitum consumption.

Experimental design: Ninety, day-old Japanese quail chicks were randomly divided into 2 equal groups i.e. control group (CX) and SBT (at the level of $2 \%$ in diet) treated group (SX) with 45 birds in each. Three replicate pens of 15 quail chicks were assigned to each group. The dietary treatment was started from day 1 and continued up to 21 days for the study of growth response, clinico-biochemical parameters and the gross and histopathological studies.

Clinical signs, growth rate, mortality and serum biochemistry: Birds from each group were closely observed, at least thrice daily, for the development of clinical signs and mortality, if any. In order to evaluate the effect of SBT leaf powder on the weekly body weights, 9 randomly selected quail chicks (three per replicate) from each group were weighed on $0,7,14$ and 21 day post feeding (DPF). After weighing, $2 \mathrm{ml}$ of blood was collected via cardiac puncture from 6 randomly selected birds from each group on 7, 14 and $21 \mathrm{DPF}$ for the estimation of serum alanine transaminase (ALT), total serum proteins (TSP), albumin, cholesterol and uric acid. All the biochemical estimations were done using diagnostic kits (Reckon Diagnostics Pvt. Ltd., Baroda, India) in a Blood Chemistry Analyzer (RA-50 Auto Chemistry System) as per the manufacturer's recommendations.

Gross pathology and histopathology: Six randomly selected quail chicks (two per replicate) were euthanized from each group at 7, 14, and 21 DPF and also examined for gross lesions, if any. Representative tissue samples were collected from liver, kidneys, spleen, heart, bursa, proventriculus etc. in $10 \%$ neutral buffered formalin for histopathological studies. Fixed tissues were trimmed, embedded in paraffin, sectioned at 3-5 $\mu \mathrm{m}$, and stained with haematoxylin and eosin [16]. 


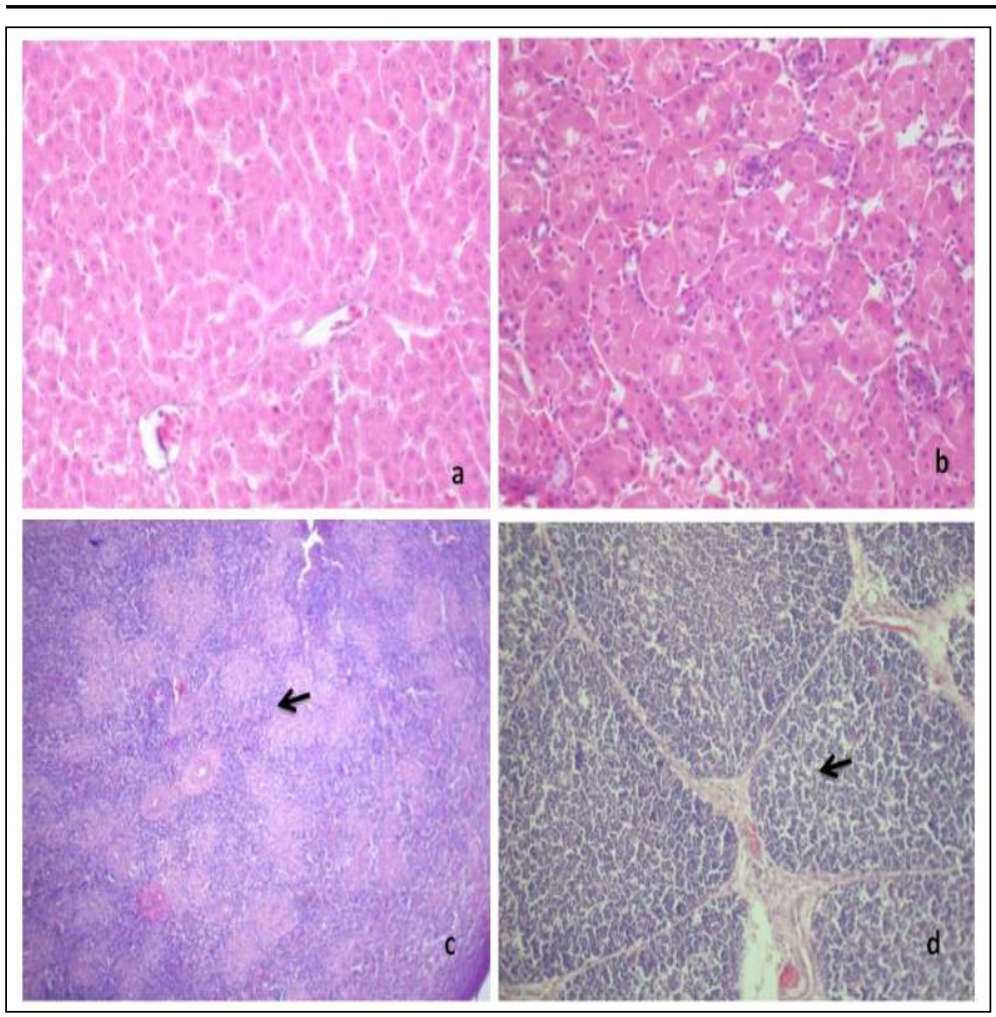

Figure-2. Photomicrographs of liver, kidney, spleen and bursa.

a. SBT group (SX) bird showing normal histological appearance liver.

b. SBT (SX) group showing normal renal architecture c. SBT group (SX) bird showing active lymphoid proliferation in spleen.

d. SBT (SX) group showing enlarged bursal follicles (arrow)

Statistical analysis: Data generated in the present study were subjected to statistical analysis by paired student's $t$ - test for calculation and comparison of mean values between the groups at various intervals. A level of significance was based on the $95 \%$ level of probability. The results were expressed as mean \pm standard error (SEM).

\section{Results}

Clinical sign, mortality and growth response: In SBT leaf powder fed group (SX) no clinical signs and mortality was recorded throughout the experiment. The SBT treated birds showed almost equal weekly body weight in comparison to those in the control birds. (Figure-1).

Biochemical parameters: The results of the various biochemical parameters at different intervals are presented in Table-1. No significant difference was observed in the values of serum ALT, total protein, albumin and uric acid of SBT treated group (SX) in comparison to control group $(\mathrm{CX})$ at different intervals of the experiment. However, serum cholesterol values were found to be non-significantly higher in SBT treated group at various intervals of the study.

Gross pathology: In the liver and kidneys, mild swelling and paleness were the only gross changes were recorded in few birds of group SX at various intervals. No major gross finding was observed in other organs.

\section{Microscopic pathology}

Liver: Liver sections in group SX chicks revealed mild to moderate congestion and vacuolar changes at various intervals (Figure-2a) of the experiment. These changes were comparable with those in the group CX birds.
Kidneys: The sections of the kidneys revealed proximal convoluted tubules (PCTs) with clear brush bordered epithelium, distal convoluted tubules (DCTs) and glomeruli with clearly visible capsular spaces in the renal cortex. The medullary region of the kidneys showed collecting tubules, collecting ducts and thick and thin segments of loops of Henle with normal epithelium. In SBT treated group mild to moderate congestion was recorded along with a slight accumulation of hyaline material in the tubular epithelial cells at various intervals of the experiment. However it, comparable to those in the control birds (Figure-2b).

Heart: The heart sections of SBT treated group chicks did not reveal any significant change at any interval of the experiment and comparable to those in the control group. The muscle fibers appeared normal with striations intact and oval shaped nuclei throughout the experiment.

Spleen: In group CX splenic red and white pulp were distinct and normal in proportion. Spleen sections of group SX showed mild reticuloendothelial and marked lymphoid cell hyperplasia at various intervals (Figure$2 c)$. In addition, mild hyperplastic changes in reticuloendothelial cells lining the periarteriolar sheath was also noted at 21 DPF.

Bursa: Normal bursa with well distinct lymphoid tissue was found in both groups. However, at $21 \mathrm{DPF}$ the follicular size in group SX was found to be larger along with plenty of lymphoid element. (Figure-2d) in comparison to those in the control $(\mathrm{CX})$.

Thymus: In group SX, thymus was found comparable to control group $(\mathrm{CX})$ at all the intervals with normal lymphoid tissue. 
Provertriculus: The control group (CX) showed mild periductal congestion whereas lymphoid nodules in the subepithelial tissue and in the proventricular gland were normal with abundant lymphoid tissue. In group SX, mild periductal congestion along with dilatation of the duct of proventricular glands containing plenty of cellular debris and mucus were the characteristic findings at 14 DPF. However, lymphoid tissue in the proventricular gland was abundant and comparable to those in the control.

Intestine: In group CX, duodenum revealed tall cylindrical villi with well intact epithelium admixed with a few goblet cells were seen. The lymphoid element in the caecal tonsil was comparable to those in control with normal villus structure. In group SX, except for mild swelling and hyperplastic changes in the lining epithelial cells of villi in the duodenum at 14 DPF, no other significant change was observed throughout the period of study.

\section{Discussion}

Results of the present study showed that addition of SBT leaf powder in feed produced no adverse effect on the growth response and survivability of the treated birds. Earlier, Chen et al. [17] supplemented the basal diet of broiler chicken with $0.25 \%, 0.5 \%$ and $1 \%$ SBT leaves, respectively and found that $0.5 \%$ SBT leaves were beneficial to the growth performance in Arbor Acres broilers and 1\% SBT leaves improved absorption of the calcium and phosphorous and the deposition of calcium. Sharma et al. [18] also reported that addition of SBT cake in poultry feed up to $30 \%$ replacement of crude protein showed better growth response and feed conversion ratio. In the present study, different biochemical parameters favored the fact that addition of SBT leaf powder in feed produces no harmful effects on the liver, kidneys and other body organs. The mean total serum albumin, total protein, ALT and uric acid concentration were found more or less similar to CX during the experiment. Cholesterol concentration in SBT group showed non significantly higher serum values in comparison to control group. This finding is also supported by gross and histopathological findings of liver with mild paleness and enlargement in SBT group which might be due to the presence of fat vacuoles in the hepatocytes as detected by histopathologically. This finding further suggested that SBT might have stimulated the cholesterol biosynthesis. Igarashi et al. [19] also reported that in the rats given cholesterolfree diet the level of serum triacylglycerols in the quercetin group (seabuckthorn flavonoid) was significantly higher as compared to those in the control. Histopathologically, the tissue architecture at various organs in SBT treated group was found comparable to those in the control except for the proliferation of lymphoid structure in different lymphoid organs. This proliferation of lymphoid element in different lymphoid tissue like spleen, bursa and caecal tonsils indicated toward some immunostimulatory potential of SBT leaves in quail. In an earlier study [3] SBT leaf and fruit extract found to stimulate lymphocyte proliferation in vitro without any kind of stimulant. Few researchers also demonstrated the hepatoprotective effect of SBT leaves extract in rats during $\mathrm{CCl}_{4}$ induced hepatic damage $[1,20]$ and against aflatoxicosis in poultry birds [10].

Since the SBT leaves, containing high crude protein, amino acid, calcium and phosphorous, they have certain advantages for basic materials to formulate feed for livestock and poultry. In the development of formula food from SBT more attention should be paid to the selection of food components, conducting tests and consideration of production and marketing, etc. The body weights of livestock and poultry were increased [21,22] considerably after feeding with leaves, seeds and fruit residues of SBT. The experiment showed that the body weights of piglets were increased $9.38 \%$ after 60 days feeding with SBT and the amount of milk produced by goats was also increased $5.74 \%$ after 40 days. The rate of laying eggs and the number of eggs were also increased $10.3 \%$ and $28.1 \%$ for 2 -year-old hens. The weight of chickens increased $5.74 \%$ and that of hens $7.81 \%$ after feeding with SBT leaves and fruit residues for 56 days $[21,22]$. The leaves and fruit residues of SBT can be treated by such methods as silaging, aminating or basification in order to decrease the content of crude fiber, increase the digestibility of crude fiber and dainty for livestock and poultry. Research in the development of formula food, pre-food and food additives of SBT should provide for conditions of great potential and markets [21].

\section{Conclusion}

Addition of seabuckthorn leaf powder at $2 \%$ level in poultry feed was found to be safe for Japanese quail on the basis of growth response, biochemical and the gross and histopathological studies. Moreover, it has some immunostimulatory potential resulting in proliferation of lymphoid tissues in various lymphoid organs.

\section{Authors' contributions}

VP, RKA and RDP designed the study. VP collected the research material and done the whole bench work. RKA had given guidance during the study. VP, RKA, and RDP drafted and revised the manuscript. All the authors had read and approved the final manuscript.

\section{Acknowledgements}

The authors are grateful to the Head, Department of Pathology and the Dean, Dr. G. C. Negi College of Veterinary and Animal Sciences, CSK HP Krishi Vishwavidyalaya Palampur for providing the necessary facilities and fund to undertake this work.

\section{Competing interests}

The authors declare that they have no competing interests

\section{References}

1. Geetha, S., Jayamurthy, P., Pal, K., Pandey, S., Kumar, R. and 
Sawhney, R.C. (2008) Hepatoprotective effects of seabuckthorn (Hippophae rhamnoides L.) against carbon tetrachloride induced liver injury in rats. J. Sci. Food Agril. 88:1592-1597.

2. Zhang, W., Zhao, J., Wang, J., Pang, X., Zhuang, X., Zhu, X. and Qu, W. (2010) Hypoglycemic effect of aqueous extract of seabuckthorn (Hippophae rhamnoides L.) seed residues in streptozotocin-induced diabetic rats. Phytother. Res. 24: 228-232.

3. Maheshwari, D.T., Yogendra Kumar, M.S., Verma, S.K., Singh, V.K. and Singh, S.N. (2011) Antioxidant and hepatoprotective activities of phenolic rich fraction of Seabuckthorn (Hippophae rhamnoides L.) leaves. Food Chem. Toxicol. 49:2422-2428.

4. Upendra Sharma, Sharma, K., Sharma, N., Sharma, A., Singh, H.P. and Sinha, A.K. (2008) Microwave-assisted efficient extraction of different parts of Hippophae rhamnoides for the comparative evaluation of antioxidant activity and quantification of its phenolic constituents by reversephase high performance liquid chromatography (RPHPLC). J. Agril. Food Chem. 56:374-379.

5. Yogendra Kumar M.S., Ruma, D., Dipti, P. and Kshipra, M. (2011) Subcritical water extraction of antioxidant compounds from seabuckthorn (Hippophae rhamnoides) leaves for the comparative evaluation of antioxidant activity. Food Chem.127:1309-1316.

6. Kallio, H., Yang, B. and Peippo, P. (2002) Effects of different origins and harvesting time on vitamin C, tocopherols and tocotrienols in seabuckthorn (Hippophae rhamnoides L.) berries. J. Agril. Food Chem. 50: 6136-6142.

7. Geetha, S., Sai Ram, M., Mongia, S.S., Singh, V., Ilavazhagan, G. and Sawhney, R.C. (2003) Evaluation of antioxidant activity of leaf extract of seabuckthorn (Hippophae rhamnoides L.) on chromium (VI) induced oxidative stress in albino rats. Mol. Cell Biochem. 87:247-51.

8. Ganju, L., Padwad, Y., Singh, R., Karan, D., Chanda, S., Chopra, M.K., Bhatnagar, P., Kashyap, R. and Sawhney, R.C. (2005) Anti-inflammatory activity of seabuckthorn (Hippophae rhamnoides) leaves. Int. Immunopharmacol. 5:1675-1684.

9. Ramasamy, T., Varshneya, C., and Katoch, V. C. (2010). Immunoprotective effect of seabuckthorn (Hippophae rhamnoides) and glucomannan on $\mathrm{T}-2$ toxin-induced immunodepression in poultry. Vet Med Int. doi: 10.4061/ 2010/149373.

10. Thakur, A., Gabru, A. and Varshneya, C. (2011) The mycotoxin protective action of seabuckthorn leaves in poultry birds. National Conference on Seabuckthorn. pages. 154-161.

11. Liu, X.C., He, G.Y. and Zhang,L.H. (1989) Taxonomical experiment of seabuckthorn leaves and residues and effect to livestock productivity. Hippophae 3: 25-29.

12. Biswas, A., Bharti, V.K., Acharya, Pawar, D.D. and Singh, S.B. (2010) Sea buckthorn: new feed opportunity for poultry in cold arid Ladakh region of India. World's Poultry Science Journal, 66:707-714.

13. Guan, T.T.Y., Cenkowski, S. and Hydamaka, A. (2005) Effect of drying on the nutraceutical quality of sea buckthorn (Hippophae rhamnoides L. ssp. Sinensis) leaves. J Food Sci. 70: E514-E518.

14. Geetha, S. and Gupta, A. (2011) Medicinal and therapeutic potential of Sea buckthorn (Hippophae rhamnoides L.). J Ethnopharmac. 138: 268-278.

15. Kumar, R., Kumar, G.P., Chaurasia, O.P. and Singh, S.B. (2011) Phytochemical and pharmacological profile of Seabuckthorn oil: a review. Res J Med Plant. 5: 491-499.

16. Luna, L. G. (1968) Manual of histologic staining methods of the Armed Forces Institute of Pathology. 3rd Ed. McGraw Hill Book Company, New York.

17. Chen, X., Zhao W., Liu, H.N., Su, J.,Zhang Z.H. and Li, Y. (2011) Effect of sea buckthorn leaves on growth performance and calcium metabolism in Arbor Acres broilers. Dongbei Nongye Daxue Xuebao,42: 19-24.

18. Sharma, V.K., Shama, S., Rani, D., Parmar, A. and Singh, V. (2011) To increase the poultry broiler production by probiotic addition in the seabuckthorn cake based ration. National Conference on Seabuckthorn. page no. 228-234.

19. Igarashi, K. and Ohmuma, M. (1995) Effects of isorhamnetin, rhamnetin, and quercetin on the concentrations of cholesterol and lipoperoxide in the serum and liver and on the blood and liver antioxidative enzyme activities of rats. Biosci Biotechnol Biochem 59:595-601.

20. Geetha, S., Sai Ram, Singh, V., Ilhavazhagan, G. and Sawhney, R.C. (2002) Antioxidant and immunomodulatory properties of seabuckthorn (Hippophae rhamnoides) - An in vitro study. J. Ethanopharmacol. 79: 373-378.

21. Hu, J. Z. (2000) Eco-economic values \& comprehensive development techniques of seabuckthorn. Zhengzhou: The Yellow River Water Conservancy Press (in Chinese).

22. Hu, J.Z. and Guo, X.F. (2006) Evaluation of nutrient value of seabuckthorn in north China. Forestry Studies in China.8:50-52. 